\title{
Assessment of dysfunctional teams
}

\author{
John D Ward
}

The multidisciplinary medical team is now a prominent feature of our modern medical care system. Over the last 40 years the 'medical team' or 'firm' has changed in many ways resulting in a way of working which can be deeply satisfying for the team members and beneficial to patients they care for. However, if the team does not function well as a unit the reverse can apply, with much dissatisfaction among staff, and substandard treatment of patients. This short article is a personal view of how things go wrong and how to improve matters based on personal experience of dysfunctional teams.

\section{Things can go wrong}

On the basis that a happy functioning team is good for patient care and pleasant to work in, a seriously dysfunctional team could well harm patients. The College is aware of instances where a team that has ceased to function well has damaged patient care, and on a number of occasions has produced a poisonous atmosphere in which to work.

Some consultants who treat their patients with courtesy and considerable clinical skill nevertheless find it difficult to fulfil their position in a multidisciplinary team. They feel that their status is inherently superior to that of any other member of the team and consider themselves de facto leader of the team. They may reflect the attitudes of consultants they met in their training or cannot come to terms with the new concept of team working. However, to blame only the consultant is unfair and inaccurate, since any member of the team may display the attitude of a non-team player. The undoubted improvement in the professional status of many members of the team is a potential source of trouble, eg when different professionals may be offering the same service and advice to a patient but are aware of a wide discrepancy in salary. These are sensitive areas that should be acknowledged if serious problems are to be avoided.

Nevertheless, it is the consultant who has the ultimate responsibility for the outcomes of treatment and this must be acknowledged, although increasingly individual professionals other than doctors may have to answer for their clinical actions.

\section{Causes of dysfunction}

A team that never meets can hardly qualify for the title of team, but lack of such meetings is probably a sign that there are problems within the team. Lack of respect for the views of any member of the team will similarly be a clear demonstration of a poor team. It follows that the most common single reason for dysfunction is poor communication between team members. Poor communication in many areas lies at the root of many real problems in clinical medicine: within the team; in the consultation with the patient; in talking to patients' families; and in conveying the increasing amount of information to be given to patients, driven by a public ever more demanding of information.

Of course, there will be occasions when even a good team will function poorly, particularly when lack of resources and an exceptionally heavy workload coincide; even the most dedicated team may begin to fall apart and appear dysfunctional in the face of such pressure.

With the growth in the numbers of consultants in many specialties, tensions may arise where three or four consultants are all members of the same multidisciplinary team. The structure of training and career advancement in the medical profession tends to produce ambitious, hard-working and strongwilled doctors and the proximity of three or four such individuals in one unit is likely to create tensions. For example, should the senior or older consultant always be the leader? It can cause irritation and resentment when management suggest or appoint a younger consultant to be clinical leader, sometimes over the head of the doctor who initially developed the service.

The battle for private practice can also be a source of poor relationships within such a team, with devastating effects on the working and morale of the whole team and on patient care.

\section{Prevention and solutions}

If what is taught early in training really has an important influence on future behaviour, it is important that training in teamwork is begun at the earliest possible stage. Appraising the team in which doctors gain experience also helps to maintain standards.
John D Ward MD FRCP, Coordinator for Invited Clinical Reviews, Royal College of Physicians 
Who is to appraise a team? It would be possible to appraise team leaders by auditing how their team functions, but this would require more administrative work from busy doctors. A large team with a heavy clinical workload and much administrative and financial work would benefit from having a team or unit manager to support the clinicians in their endeavours.

\section{Management of dysfunctional teams}

What can one do with a team that is already seriously dysfunctional? When problems suggesting a poorly functioning team with perhaps unacceptable patient care are first brought to the notice of a clinical or medical director, they will want to assess the situation for themselves and try to identify the source of the problem. Often the problem will not come as a surprise to an experienced medical director but there may be a limit to his or her ability to alter the situation. In such a case, it is probably wise to obtain an outside opinion from a Royal College, specialist society or the National Clinical Assessment Authority if the situation is serious. Such a visit and assessment may confirm what management already suspect or it may uncover other factors, good or bad. In that way, an ad hoc informal peer review may be more helpful to the unit than a formal review. Any visiting group asked to look at such a dysfunctional unit should be briefed in detail. During the same visit, it may look at other local problems and carry out a form of peer review of clinical services. It is important that the visitors should be clear about the objectives of the visit, based on information provided about the poorly functioning team.

Major disruption of teamwork may be caused when one or more team members do not communicate or arrogantly disregard the feelings and wishes of their colleagues. They may not be aware of their disruptive behaviour, so bringing it to their attention may be enough for them to change. However, although total lack of insight is uncommon, when it is the cause of the problem it may be very difficult to find solutions.

The whole team may benefit from having an 'away day'. The whole team, and if possible a manager associated with the team, should meet off the site of work and, working to a planned agenda, talk through as many aspects of their work as possible, including the problems that have been noticed. They should try to come to an agreement about how to solve their problems. An independent facilitator should lead the team in this process; most health authorities know of such facilitators who have often had appropriate training for such a task. Many good teams voluntarily organise such sessions to assess their own standards. If good teams can do this, then those few bad teams can hardly fail to accept such advice. A visit or secondment of team members to other teams that are functioning well may also be helpful in maintaining their own team's standards.

\section{Conclusion}

Multidisciplinary team working is the norm in modern healthcare and most teams work impressively well, creating a happy and satisfying working environment and providing an excellent clinical service to patients. A few teams do not function well, usually due to difficult individuals who allow their own needs and ambitions to get in the way of patient care. The situation is often aggravated by poor communications between team members. They present a depressing picture which contrasts with the positive attitude found in successful teams. 